\title{
Allergy and risk of childhood leukaemia: Results from the UKCCS
}

\author{
Ann M. Hughes ${ }^{1}$, Tracy Lightfoot ${ }^{1}$, Jill Simpson ${ }^{1}$, Pat Ansell ${ }^{1}$, Patricia A. McKinney ${ }^{2}$, Sally E. Kinsey ${ }^{3}$, \\ Christopher D. Mitchell ${ }^{4}$, Tim O.B. Eden ${ }^{5}$, Mel Greaves ${ }^{6}$ and Eve Roman ${ }^{1 *}$ on behalf of the United Kingdom \\ Childhood Cancer Study Investigators \\ ${ }^{1}$ Epidemiology and Genetics Unit, Department of Health Sciences, University of York, York, United Kingdom \\ ${ }^{2}$ Paediatric Epidemiology Group, University of Leeds, Leeds, United Kingdom \\ ${ }^{3}$ Department of Paediatric and Adolescent Oncology and Haematology, St James University Hospital, Leeds, UK \\ ${ }^{4}$ Department of Haematology/Oncology, John Radcliffe Hospital, Oxford, United Kingdom \\ ${ }^{5}$ Academic Unit of Paediatric Oncology, Christie Hospital NHS Trust, Withington, Manchester, United Kingdom \\ ${ }^{6}$ Institute of Cancer Research, Chester Beatty Laboratories, London, United Kingdom
}

\begin{abstract}
We investigated the relationship between childhood leukaemia and preceding history of allergy. A nationwide case-control study of childhood cancers was conducted in the United Kingdom with population-based sampling of cases $(n=839)$ and controls $(n=$ $1,337)$, matched on age, sex and region of residence. Information about clinically diagnosed allergies was obtained from primary care records. More than a third of subjects had at least one allergy diagnosed prior to leukaemia diagnosis (cases) or pseudo-diagnosis (controls). For both total acute lymphoblastic leukaemia (ALL) and common-ALL/precursor B-cell ALL (c-ALL), a history of eczema was associated with a $30 \%$ significant reduction in risk: the odds ratios $(\mathrm{OR})$ and $95 \%$ confidence intervals $(\mathrm{CI})$ were 0.70 $(0.51-0.97)$ and $0.68(0.48-0.98)$, respectively. Similar associations were observed for hayfever (OR $=0.47 ; 95 \%$ CI: $0.26-0.85$ and $\mathrm{OR}=0.62 ; 95 \% \mathrm{CI}: 0.33-1.16$ for ALL and c-ALL, respectively). No such patterns were seen either for asthma and ALL, or for any allergy and acute myeloid leukaemia. A comparative analysis of primary care records with parents recall of allergy revealed only moderate agreement with contemporaneous clinical diagnoses for both cases and controls-confirming the unreliability of parental report at interview. Our finding of a reciprocal relationship between allergy and ALL in children is compatible with the hypothesis that a dysregulated immune response is a critical determinant of childhood ALL.

(C) 2007 Wiley-Liss, Inc.
\end{abstract}

Key words: child; allergy; leukaemia; lymphoblastic; acute; casecontrol

There is increasing evidence to support the notion that an abnormal immune response is a critical determinant of childhood acute lymphoblastic leukaemia (ALL). Hitherto, the majority of epidemiological research has focussed on the potential aetiological roles of the timing and dose of infection. ${ }^{1,2}$ However, in the context of the maturation of the immune system, investigating the relationship between allergy and ALL may provide more insight into the possible mechanisms involved. The way by which allergy might influence childhood leukaemia risk is not clear, although one possibility is that individuals with allergic conditions have immune systems with a greater capacity to detect and destroy aberrant cells.

Whilst most studies of allergy and childhood leukaemia ${ }^{3-12}$ report an inverse association, data on the specific allergy types involved and the extent of the reduction in risk is uncertain. This is partly because most investigations to date have relied on parental recall to measure their child's allergy history and obtaining accurate unbiased information about prior illnesses at interview is recognised as being problematic. In addition to recall bias, questioning is not always comprehensive and, even where it is, substantial misclassification of allergies might be expected.

We describe here the results of an analysis based on data abstracted from contemporaneously compiled primary care clinical records as part of the largest and most comprehensive population-based case-control study of paediatric cancers: the United
Kingdom Childhood Cancer Study (UKCCS). The ability to access complete sets of medical records from an individual's general practitioner in this way is a unique feature of the UK health care system. Importantly, in our study, we were also able to assess the agreement between an individual's parental reports of asthma and eczema with their clinically diagnosed reports and compare relative risk estimates from the two sources.

\section{Material and methods}

Study population

Details of the UKCCS have been described elsewhere. ${ }^{13}$ Briefly, cases diagnosed with a malignancy between 1991 and 1996, aged 14 or younger and resident in Great Britain were recruited to the study. Controls were randomly selected from primary care population registers and individually-matched to participating cases by age, sex and study region with two controls per case. The age of diagnosis of leukaemia of the case was designated as the age at pseudodiagnosis for the corresponding matched $\operatorname{control}(\mathrm{s})$.

\section{Data collection}

Detailed diagnostic information was obtained from multiple sources, including the Medical Research Council's treatment trials, to classify leukaemia subtypes. ${ }^{13}$ Information regarding the index child's health was collected from mothers, using interviewer-administered questionnaires. In addition, lifetime histories of childhood diseases, including allergies, were systematically abstracted from primary care records compiled prior to diagnosis/ interview. ${ }^{14}$ Items abstracted included all consultations with a general practitioner or practice nurse, referrals to hospital consultants and other specialists, dates of individual events, results of tests and investigations along with details relating to prescribed medicines and other treatments. Symptoms and diagnoses were coded using the Tenth Revision of the International Classification of Diseases (ICD-10). ${ }^{15}$ Drugs were coded using a schema based on the British National Formulary. ${ }^{16}$

Dates and diagnoses of the following conditions were recorded from each subject's records for the period from birth to diagnosis/ pseudodiagnosis: asthma, hayfever or allergic rhinitis (hereafter referred to simply as 'hayfever') and eczema, atopic eczema or atopic dermatitis (hereafter referred to simply as 'eczema'). Pre-

A complete list of grant sponsors is given in the Acknowledgements.

See Appendix for Management Committee, Regional Investigators and Data Processing Group.

*Correspondence to: Epidemiology and Genetics Unit, Department of Health Sciences, University of York, YO10 5DD, UK.

Fax: +44-0-1904-321-899. E-mail: eve.roman@egu.york.ac.uk

Received 9 January 2007; Accepted after revision 13 February 2007

DOI 10.1002/ijc.22702

Published online 27 March 2007 in Wiley InterScience (www.interscience. wiley.com). 
TABLE I - SAMPLE CHARACTERISTICS BY DISEASE STATUS, UKCCS STUDY

\begin{tabular}{|c|c|c|c|c|c|c|c|c|c|}
\hline & \multirow[b]{3}{*}{$\begin{array}{c}\text { Controls } \\
(n=1337) \\
n(\%)\end{array}$} & \multirow{2}{*}{\multicolumn{2}{|c|}{ All leukaemias combined }} & \multicolumn{4}{|c|}{ Acute lymphoblastic leukaemias (ALL) } & \multirow{2}{*}{\multicolumn{2}{|c|}{ Acute myeloid leukaemias }} \\
\hline & & & & \multicolumn{2}{|c|}{ Total ALL } & \multicolumn{2}{|c|}{ common-ALL } & & \\
\hline & & $\begin{array}{c}\text { Cases } \\
(n=839) \\
n(\%)\end{array}$ & $p$-value ${ }^{1}$ & $\begin{array}{c}\text { Cases } \\
(n=720) \\
n(\%)\end{array}$ & $p$-value ${ }^{1}$ & $\begin{array}{c}\text { Cases } \\
(n=538) \\
n(\%)\end{array}$ & $p$-value ${ }^{1}$ & $\begin{array}{c}\text { Cases } \\
(n=101) \\
n(\%)\end{array}$ & $p$-value ${ }^{1}$ \\
\hline \multicolumn{10}{|l|}{ Gender } \\
\hline Male & $728(54.4)$ & $454(54.1)$ & & $391(54.3)$ & & $293(54.5)$ & & $52(51.5)$ & \\
\hline Female & $609(45.6)$ & $385(45.9)$ & 0.88 & $329(45.7)$ & 0.95 & $245(45.5)$ & 1.00 & $49(48.5)$ & 0.56 \\
\hline \multicolumn{10}{|l|}{ Deprivation index } \\
\hline Least deprived 1 & $315(23.6)$ & $186(22.2)$ & & $161(22.4)$ & & $121(22.5)$ & & $21(20.8)$ & \\
\hline 2 & $291(21.8)$ & $181(21.6)$ & & $161(22.4)$ & & $122(22.7)$ & & $18(17.8)$ & \\
\hline 3 & $314(23.5)$ & $164(19.5)$ & & $139(19.3)$ & & $110(20.5)$ & & $21(20.8)$ & \\
\hline 4 & $239(17.9)$ & $163(19.4)$ & & $141(19.6)$ & & $100(18.6)$ & & $18(17.8)$ & \\
\hline Most deprived 5 & $173(12.9)$ & $143(17.0)$ & 0.03 & $116(16.1)$ & 0.09 & $83(15.4)$ & 0.44 & $23(22.8)$ & 0.09 \\
\hline Missing & $5(0.4)$ & $2(0.2)$ & & $2(0.3)$ & & $2(0.4)$ & & $0(0.0)$ & \\
\hline \multicolumn{10}{|l|}{ Breastfed } \\
\hline Ever & $862(64.5)$ & $516(61.5)$ & & $445(61.8)$ & & $329(61.1)$ & & $61(60.4)$ & \\
\hline Never & $475(35.5)$ & $323(38.5)$ & 0.16 & $273(37.9)$ & 0.23 & $208(38.7)$ & 0.18 & $40(39.6)$ & 0.41 \\
\hline Missing & $2(0.1)$ & $2(0.2)$ & & $2(0.3)$ & & $1(0.2)$ & & $0(0.0)$ & \\
\hline \multicolumn{10}{|l|}{ First born } \\
\hline Yes & $579(43.3)$ & $360(42.9)$ & & $310(43.1)$ & & $236(43.9)$ & & $42(41.6)$ & \\
\hline No & $758(56.7)$ & $479(57.1)$ & 0.86 & $406(56.4)$ & 0.91 & $302(55.7)$ & 0.82 & $59(58.4)$ & 0.74 \\
\hline Missing & $4(0.3)$ & $4(0.5)$ & & $4(0.5)$ & & $2(0.4)$ & & $0(0.0)$ & \\
\hline
\end{tabular}

${ }^{1}$ Derived from two-sample test for proportions comparing cases and controls without missing variables for the variable.

scriptions for nasal, inhaled or oral corticosteroids, antihistamines and bronchodilators were noted.

Enumeration district 'deprivation' indices (in quintiles) based on car ownership, housing tenure, household overcrowding and unemployment ${ }^{17}$ were calculated for the household at diagnosis/ pseudodiagnosis ${ }^{13}$ and used as a measure of socioeconomic status.

\section{Definitions of allergy}

Probable asthma, hayfever and eczema were all defined as at least one episode for which a diagnosis of one of these conditions was recorded in the medical notes. Episodes where the documentation indicated ambiguity in the allergy diagnosis were censored.

Definite asthma was asthma with evidence of one or more prescriptions for drugs typically used to treat this condition recorded in the medical records.

Definite hayfever was hayfever with evidence of one or more prescriptions for drugs typically used to treat this condition in the medical records.

Definite eczema was defined using information from both medical records and interview. In addition to a clinical record (as earlier), definite eczema was that which, according to mother's report, affected the body skin folds or flexures (i.e., the folds of the elbows, behind the knees, in front of the ankles, under the buttocks or around the neck, ears and eyes); flexural involvement is a major feature of eczema and used as a criterion in the diagnosis of this condition. ${ }^{18}$

\section{Statistical methods}

Altogether, 3,838 children with cancer, including 1,736 with leukaemia and 7,629 control children were studied as part of the UKCCS. ${ }^{13}$ The present analyses are restricted to the six study regions that systematically abstracted primary care records across all, or specific parts of, their area. ${ }^{14}$ Overall, medical records for $1,597(92 \%)$ children with cancer and $2,393(70 \%)$ control children were abstracted; of these, $890(56 \%)$ were leukaemia cases and $1,375(57 \%)$ were matched controls. Children with Down's syndrome $(n=27)$ and those aged less than 3 months at diagnosis/pseudodiagnosis $(n=23)$ were excluded. Allergies diagnosed in the 3 months prior to diagnosis/pseudodiagnosis date $(n=39)$ were also censored, leaving 839 leukaemia cases and 1,337 matched controls available for analysis.

Records for at least one matched control were abstracted for every case, with more than half having information abstracted for both of their matched controls. Importantly, where information was abstracted for only one control, this control was the first to be randomly selected and was identified in advance of abstraction. To exclude the possibility that any observed association was due in part to selection bias, analyses were repeated using only subjects from the Oxford region as this was the only study region to routinely abstract data for both controls throughout.

Odds ratios (OR) and 95\% confidence intervals (CI) were estimated for a composite variable ('at least one allergy') and for individual allergies in unconditional logistic regression models and adjusted for deprivation and the three matching variables: sex, age at diagnosis (in single years) and region of residence at diagnosis. Analyses were conducted in parallel for all leukaemias combined and for 3 subgroups: ALL, common-ALL/precursor B cell (c-ALL) and acute myeloid leukaemia (AML). Small sample size prevented T-cell ALLspecific analyses. To increase precision, all available leukaemia controls were used as the comparison for each diagnostic subgroup. Tests for linear trend were conducted by fitting ordered categories of a variable as a single ordinal variable in the models; trend $p$-values were based on the Wald test. All analyses were conducted using Stata software (version 9.2) (StataCorp, College Station, Texas, 2006).

During the interview, subjects' parents were asked if their child had ever had asthma or eczema (there were no direct questions about hayfever in the interview). We evaluated the accuracy of 1,843 parental reports of allergy history, using a measure of sensitivity (true positive proportion); this was calculated by dividing the number of asthma or eczema diagnoses recorded by both interview and records by the total number of asthma or eczema diagnoses identified in the records. Overall agreement between interview and records was measured using the kappa ( $\kappa)$ statistic. Sensitivity and $\kappa$ were calculated separately for cases and controls. To examine the effects of differential misclassification, whereby cases either over- or under-report compared to controls, risk estimates for the association between allergy history and risk of ALL from each dataset were also compared.

\section{Results \\ Subject characteristics}

Seven-hundred and twenty (86\%) of the 839 leukaemias were acute lymphoblastic and $101(12 \%)$ were acute myeloid. The sex distribution was comparable to previously reported data, with an excess of boys for all leukaemias combined and for each diagnostic subgroup (Table I). 
In general, participation was lower among control families living in more deprived areas and we have adjusted for deprivation in all subsequent analyses. Breastfeeding history (ever/never) and early birth order (firstborn: yes/no) were also examined as potential confounders since they are considered to be proxies for reduced exposure to infectious agents in infancy and, as such, thought to be associated with the development of atopic disease. The distribution of both covariates was similar amongst cases and controls, with neither covariate significantly changing the risk estimates when controlled for in the models. Therefore, the models presented here include the matching variables and deprivation index alone.

\section{Allergy history}

More than a third of cases $(n=305 ; 36 \%)$ and controls $(n=$ $523 ; 39 \%$ ) had at least one diagnosis of allergy (i.e., eczema, asthma or hayfever) in their medical records; of these, half had at least one 'definite' diagnosis (cases: $n=151$; controls: $n=288$ ) (Table II). The most common condition was eczema, with 250 (30\%) cases and $433(32 \%)$ controls having one or more recorded episode. Diagnoses of asthma and hayfever were less frequent: 85 (10\%) cases and $135(10 \%)$ controls had 'probable asthma' and only $23(3 \%)$ cases and $60(5 \%)$ controls had 'probable hayfever'. Whilst the number of subjects with positive asthma or hayfever histories remained fairly static when 'definite' diagnoses were considered, numbers of eczema diagnoses decreased by $71 \%$ in cases and $64 \%$ in controls when parental report of flexural involvement was included as a diagnostic criterion. It should be noted, however, that 71 parents of children with a 'probable eczema' diagnosis $(10 \% ; 32$ control parents and 39 case parents) were not asked about flexural involvement, as the question was only introduced in the second year of the study.

A history of at least one 'probable' allergy was associated with a $13-16 \%$ nonsignificant reduction in risk across all leukaemia subgroups (Table II). For ALL, associations were stronger for 'definite' allergy diagnoses (OR $=0.77$; 95\% CI: $0.60-0.98)$ but this wasn't seen for AML (OR $=0.92 ; 95 \% \mathrm{CI}: 0.55-1.53)$. The deficit of 'definite' allergy among ALL cases compared to controls is largely driven by eczema $(\mathrm{OR}=0.70 ; 95 \% \mathrm{CI}: 0.51-0.97)$ and hayfever $(\mathrm{OR}=0.47$; 95\% CI: $0.26-0.85)$, there being little association with asthma. The estimated odds risk ratios for c-ALL were not dissimilar to those for ALL as a whole. No associations between a diagnosis of any allergy type ('probable' or 'definite') and AML were observed; however, numbers were small and the power to detect an association was limited. Similar results were obtained when the analysis was confined to Oxford cases only (152 cases, 321 controls; data not shown). Likewise, controlling for the possible confounders did not materially affect the estimates but we have chosen to present the adjusted ORs rather than the unadjusted ORs.

\section{Comparison of interviews and records}

In Table III, subjects are characterised as positive or negative for history of asthma or eczema according to parental interviews and medical records. The medical record definition of 'probable' eczema was independent of interview reports of flexural involvement. Interview sensitivity and $\kappa$ (with $95 \% \mathrm{CI}$ ) are presented. Numbers of missing data and 'don't know' responses from the interview were similar for both allergy types. Asthma was reported with high accuracy and varied little between case and control parents (81\% sensitivity for cases; $83 \%$ sensitivity controls), but sensitivities for eczema (51-57\%) were more moderate. The measure of overall reporting agreement was also highest for asthma $(\kappa=0.63)$, with cases $(\kappa=0.69)$ exceeding controls $(\kappa=$ $0.60)$. Eczema history was frequently under-reported by mothers $(13.7 \%-14.4 \%)$ and the proportion of unsubstantiated reports (i.e., false positive and false negative reports) by case and control parents was more than twofold higher for eczema than for asthma (control parents: $22.0 \%$ vs. $9.2 \%$; case parents: $20.5 \%$ vs. $6.3 \%$ ).

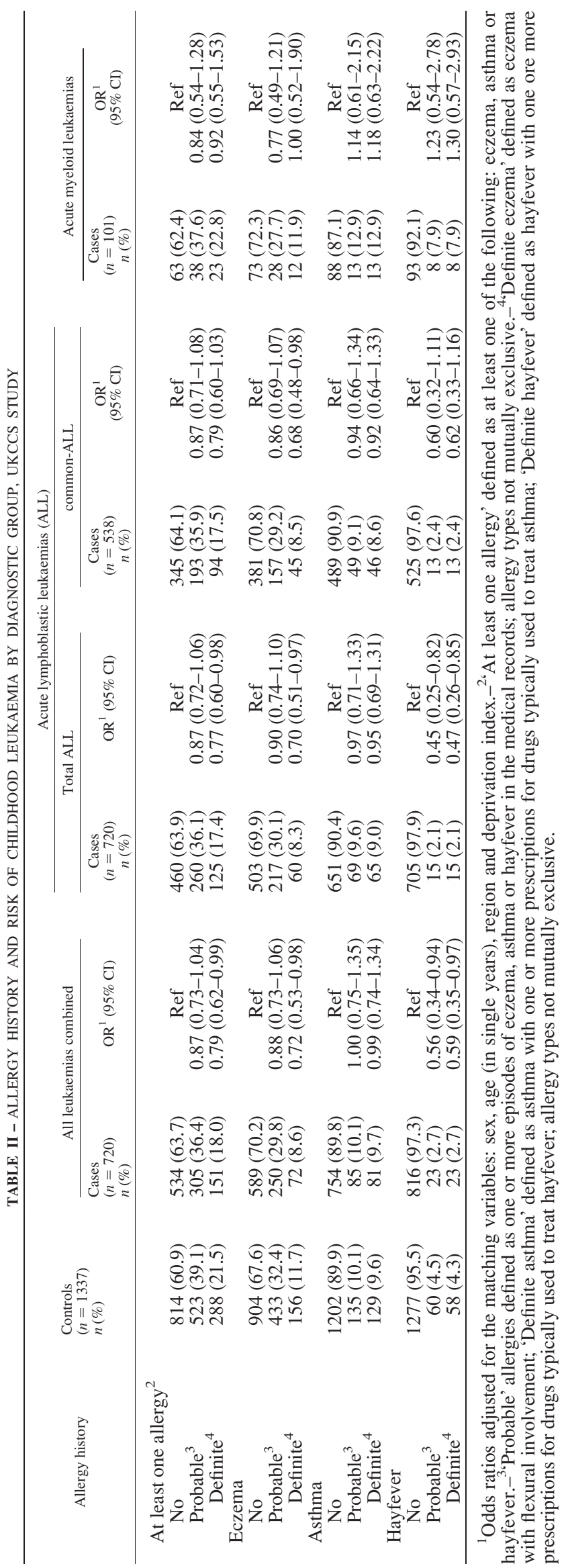


TABLE III - COMPARISON OF SELF-REPORTS OF INTERVIEWED MOTHERS WITH PRIMARY CARE RECORDS FOR HISTORY OF ECZEMA AND ASTHMA AMONG 1843 UKCCS ACUTE LYMPHOBLASTIC LEUKAEMIA CASES AND CONTROLS

\begin{tabular}{|c|c|c|c|c|c|c|c|c|c|}
\hline \multirow{2}{*}{ Allergy history ${ }^{1}$} & \multicolumn{4}{|c|}{ Interview data/Primary care records } & \multirow{2}{*}{$\begin{array}{c}\text { Missing data } \\
n(\%)\end{array}$} & \multirow{2}{*}{$\begin{array}{c}\text { Don't know }{ }^{3} \\
n(\%)\end{array}$} & \multirow{2}{*}{$\begin{array}{c}\text { Total } \\
(n)\end{array}$} & \multirow{2}{*}{ Sensitivity } & \multirow{2}{*}{ Kappa } \\
\hline & $\begin{array}{c}+/+ \\
n(\%)\end{array}$ & $\begin{array}{l}+/- \\
n(\%)\end{array}$ & $\begin{array}{c}-/+ \\
n(\%) \\
\end{array}$ & $\begin{array}{l}-/- \\
n(\%)\end{array}$ & & & & & \\
\hline \multicolumn{10}{|l|}{ Eczema } \\
\hline All & $311(16.9)$ & $139(7.5)$ & $257(13.9)$ & $1087(59.0)$ & $1(0.1)$ & $48(2.6)$ & 1843 & 0.55 & $0.46(0.42-0.51)$ \\
\hline Controls & $221(17.9)$ & $102(8.3)$ & $169(13.7)$ & $714(57.8)$ & $1(0.1)$ & $27(2.2)$ & 1234 & 0.57 & $0.46(0.41-0.52)$ \\
\hline Cases & $90(14.8)$ & $37(6.1)$ & $88(14.4)$ & $373(61.2)$ & $0(0.0)$ & $21(3.5)$ & 609 & 0.51 & $0.45(0.37-0.53)$ \\
\hline \multicolumn{10}{|l|}{ Asthma } \\
\hline All & $157(8.5)$ & $117(6.3)$ & $34(1.8)$ & $1488(80.7)$ & $0(0.0)$ & $47(2.6)$ & 1843 & 0.82 & $0.63(0.58-0.68)$ \\
\hline Controls & $106(8.6)$ & $91(7.4)$ & $22(1.8)$ & $982(79.6)$ & $0(0.0)$ & $33(2.7)$ & 1234 & 0.83 & $0.60(0.54-0.67)$ \\
\hline Cases & $51(8.4)$ & $26(4.3)$ & $12(2.0)$ & $506(83.1)$ & $0(0.0)$ & $14(2.3)$ & 609 & 0.81 & $0.69(0.60-0.78)$ \\
\hline
\end{tabular}

${ }^{1}$ Based on responses to the question: 'Has your child ever had asthma/eczema? (Interview data)'; allergy types not mutually exclusive.- ${ }^{2}$ Missing data for interview. ${ }^{3}$ 'Don't know' response to interview.

TABLE IV - RISK OF ACUTE LYMPHOBLASTIC LEUKAEMIA IN 1843 CHILDREN ASSOCIATED WITH ALLERGY HISTORY ACCORDING TO PARENTAL INTERVIEW DATA AND PRIMARY CARE RECORDS, UKCCS STUDY

\begin{tabular}{|c|c|c|c|c|c|c|c|c|}
\hline \multicolumn{4}{|c|}{ Parental interview data } & \multicolumn{4}{|c|}{ Primary care records } & \multirow[b]{2}{*}{$\begin{array}{c}\text { Difference } \\
\text { between } \mathrm{ORs}^{3}\end{array}$} \\
\hline Allergy history ${ }^{1}$ & $\begin{array}{c}\text { Controls } \\
(n=1234) \\
n(\%)\end{array}$ & $\begin{array}{c}\text { Cases } \\
(n=609) \\
n(\%)\end{array}$ & $\mathrm{OR}^{2}(95 \% \mathrm{CI})$ & Allergy history & $\begin{array}{c}\text { Controls } \\
(n=1234) \\
n(\%)\end{array}$ & $\begin{array}{c}\text { Cases } \\
(n=609) \\
n(\%)\end{array}$ & $\mathrm{OR}^{2}(95 \% \mathrm{CI})$ & \\
\hline Eczema & & & & Eczema & & & & \\
\hline Never & $883(71.6)$ & $461(75.7)$ & Ref & No & $833(67.5)$ & $427(70.1)$ & Ref & $15.6 \%$ \\
\hline Ever & $323(26.2)$ & $127(20.9)$ & $0.77(0.61-0.98)$ & Probable $^{4}$ & $401(32.5)$ & $182(29.9)$ & $0.89(0.72-1.10)$ & \\
\hline Asthma & & & & Asthma & & & & \\
\hline Never & $1004(81.4)$ & $518(85.1)$ & Ref & No & $1103(89.4)$ & $545(89.5)$ & Ref & $36.5 \%$ \\
\hline Ever & $197(16.0)$ & $77(12.6)$ & $0.74(0.55-0.99)$ & Probable $^{4}$ & $131(10.6)$ & $64(10.5)$ & $1.01(0.73-1.39)$ & \\
\hline
\end{tabular}

${ }^{1}$ Based on positive responses to the question: 'Has your child ever had asthma/eczema?'; allergy types not mutually exclusive. Odds ratios adjusted for the matching variables: sex, age (in single years), region and deprivation index.- ${ }^{3}$ Percent difference between odds ratio based on primary care records and odds ratio based on interview data.- ${ }^{4}$ Probable' allergies defined as one or more episodes of eczema, asthma or hayfever in the medical records.

Agreement between interviews and records was, therefore, only moderate for eczema $(\kappa=0.46)$ but did not differ discernibly for cases and controls.

Table IV shows the variability in estimates of risk resulting from the alternative reporting sources. In general, odds ratios calculated from record data were higher than those resulting from interview data. The odds ratios for a positive history of eczema from the interview $(\mathrm{OR}=0.77 ; 95 \%$ CI: $0.61-0.98)$ and 'probable eczema' from the records (OR $=0.89$; 95\% CI: 0.72-1.10) were both less than one, with only the interview-based estimate statistically significant. For a history of asthma, the OR derived from the interview was also statistically significant and indicative of a reduction in risk $(\mathrm{OR}=0.74$; 95\% CI: 0.55-0.99), whereas the estimate for 'probable asthma' from the records (OR $=1.01 ; 95 \%$ CI: 0.73-1.39) suggested no association between risk of ALL and asthma.

\section{Cytogenetics}

Cytogenetic data were available for 744 (89\%) children with leukaemia. There were no obvious patterns of risk associated with any of the cytogenetic subgroups $(p>0.05)$ for children with or without a diagnosis of allergy; however, some of the subgroup analyses were based on small numbers (data not shown).

\section{Discussion}

In the UKCCS, we observed a $\sim 20 \%$ reduction in risk for ALL and c-ALL following a definite diagnosis of allergy. The strongest association was observed with eczema and, to a lesser extent, hayfever, for which we observed statistically significant reductions in risk for total ALL and c-ALL of $30 \%$ and $40 \%$, respectively. There was little support for an association with asthma. By contrast, although the number of AML cases was small, the pattern of risk differed markedly from that seen for ALL and c-ALL such that there was no evidence of any relationship with allergy, which, given the heterogeneous nature of childhood leukaemia, is not entirely unexpected.

Allergies are a diverse range of conditions and the type of allergy diagnosed in childhood varies considerably with age. Eczema presents early in infancy before the peak age of childhood leukaemia, with onset between 12 and 24 months, whereas asthma and hayfever typically onset in later childhood. In our data, the mean age of diagnosis of eczema, asthma and hayfever were $1.4,3.0$ and 6.6 years, respectively. Onset prior to the age of 2 is often used as a criterion in the diagnosis of eczema ${ }^{18}$ and, as the majority (84\%) of UKCCS subjects with eczema were diagnosed before that age, we can be fairly confident that most cases were captured. Unlike eczema, however, there are no explicit diagnostic guidelines for asthma and the term includes a broad range of conditions. ${ }^{19}$ Thus, differentiating children who frequently experience respiratory asthma-like symptoms with infection from those who are truly asthmatic is not straightforward; this is probably also true for hayfever. The fact that age of onset occurs after the peak age of childhood leukaemia and that misclassification is not unlikely, suggests that asthma and hayfever may be poor markers of allergy in this population.

Paradoxically, eczema, which is less complicated to diagnose in the clinical setting, was reported by mothers less accurately than asthma. One possible explanation for this might be that diagnosis of eczema occurs further from the time of interview, thereby creating greater potential for recall bias. The fluctuating and usually less serious nature of eczema may also contribute to lower precision. Risk estimates for allergy histories were less pronounced if based on record data. Nondifferential exposure misclassification, with frequent under-reporting of eczema by both case and control parents, might be expected to bias towards the null. For maternalreported history of asthma, sensitivity was slightly higher and the proportion of true negatives was lower in controls compared to cases. As a result, measures of association between a history of asthma and risk of ALL were substantially underestimated and we 
calculated a reduction in the odds ratio of more than $36 \%$ when based on interview rather than records.

Our findings suggest that ascertaining accurate histories of some allergies by questionnaire is not straightforward and that epidemiological studies relying on parent recall may be subject to substantial bias. In particular, prevalence rates for allergies based on parental reports are likely to be underestimated for eczema and overestimated for asthma. Surprisingly, perhaps, there are no corresponding data for the UK to compare with incidence rates of allergy in our control population. There are, however, estimates for the UK derived from sources, including cross-sectional surveys, subject-reported symptoms and parental reports, ${ }^{20-25}$ which vary somewhat from the incidence of medically-recorded allergic conditions, using the 'definite' allergy definitions in our controls; for example, the UK rates for eczema, asthma and hayfever from Phase 1 (1994-95) of the ISAAC Study ${ }^{25}$ for 6-7 year-olds were $13.0 \%, 18.4 \%$ and $9.8 \%$ compared to $9.8 \%, 12.8 \%$ and $1.5 \%$, respectively, in our controls of the same age.

This is the first large-scale study to use contemporaneously collected primary care data to examine the association between childhood leukaemia and preceding allergy. Rigorous definitions of allergy were obtained by refining clinical diagnoses of eczema, asthma and hayfever, using additional criteria such as drug prescriptions and flexural eczema. Although parental reports were used to identify the subset of children with flexural rash, and misclassification is therefore possible, the evidence suggests ${ }^{26}$ that mothers are able accurately to report the presence of visible flexural dermatitis in their children. When restricting to clinicallydiagnosed allergy, the potential for incomplete ascertainment of conditions treated outside primary care is balanced by a reduction in the misclassification of allergy occurring in parental report. For example, in our control population, the primary care records revealed over $60 \%$ more children with eczema than were reported by their mothers $(32.5 \%$ and $26.2 \%$, respectively). The observed higher rate of refusal among control families in deprived areas is a common feature of case-control studies and we adjusted for deprivation index in every model to minimise the effects of any possible selection bias. However, with our recent report of a lack of association between socio-economic status and childhood leukaemia in the UKCCS,${ }^{27}$ it is unsurprising that inclusion of this covariate had little effect on reported risk estimates in these analyses.

The possible association between infections and allergy has been examined in many epidemiological studies following the advent of the 'hygiene hypothesis' in the late 1980s. ${ }^{28}$ According to this hypothesis, exposure to infections early in life propels the maturation of the immune system towards the Th1 phenotype and away from the Th2 phenotype and thus protects against diseases generated by Th2-biased immune dysfunction, such as allergies. Delayed exposure to infectious agents early in life should, therefore, increase risk of atopic disease. There are, however, continual challenges to this hypothesis. Whilst contact with farm animals ${ }^{29}$ and use of probiotics ${ }^{30}$ have been shown to protect against allergic disease, the evidence with respect to clinical infections is contradictory and suggests that only specific microbes, such as measles and tuberculosis, are protective. ${ }^{31,32}$ Further, there is evidence that the prevalence of both Th-1 and Th2-related diseases are rising and that some infections, in particular respiratory viral infections, may actually precipitate development of allergic disease. ${ }^{33}$

The most plausible biological explanation for our findings involves immune dysfunction. Since both innate and adaptive immune responses are subject to genome-wide genetic variation, functional polymorphisms in key cytokine genes may result in distinct genetic susceptibility profiles that influence the nature of immune response to infectious agents. In a recent UKCCS report ${ }^{14}$ examining the relationship between infections and ALL we found that, compared to controls, cases had more infectious episodes in infancy; the differences being most marked in the neonatal period. Thus, timing and chronicity of infectious exposure are likely to be critical in the relationship between ALL and allergy. ${ }^{34}$ We are currently evaluating the roles of both allergy and infection in the development of childhood ALL along with the potential for interaction or effect modification of the associations we have previously observed.

\section{Acknowledgements}

The United Kingdom Childhood Cancer Study is sponsored and administered by the Leukaemia Research Fund. The Study was conducted by 12 teams of investigators ( 10 clinical and epidemiological and 2 biological) based in university departments, research institutes and the National Health Service in Scotland. The work is coordinated by a Management Committee. It is supported by the UK Children's Cancer Study Group of paediatric oncologists by the National Radiological Protection Board.

Dr. Ann Maree Hughes has an Australian National Health and Medical Research Council Sidney Sax Post-doctoral Research Fellowship (NHMRC Grant ID: 358672).

We would like to thank the members of the UK Childhood Cancer Study Group for their support and staff of local hospitals, general practitioners, general practice staff and UKCCS interviewers and technicians. We would especially like to thank the families of the children included in the study, without whom, this investigation would not have been possible.

\section{References}

1. Greaves M. Infection, immune responses and the aetiology of childhood leukaemia. Nat Rev Cancer 2006;6:193-203.

2. Kinlen L. Infections and immune factors in cancer: the role of epidemiology. Oncogene 2004;23:6341-8.

3. Nishi M, Miyake H. A case-control study of non-T cell acute lymphoblastic leukaemia of children in Hokkaido, Japan. J Epidemiol Community Health 1989;43:352-5.

4. Magnani C, Pastore G, Luzzatto L, Terracini B. Parental occupation and other environmental factors in the etiology of leukemias and nonHodgkin's lymphomas in childhood: a case-control study. Tumori 1990;76:413-19.

5. Buckley JD, Buckley CM, Ruccione K, Sather HN, Waskerwitz MJ, Woods WG, Robison LL. Epidemiological characteristics of childhood acute lymphocytic leukemia. Analysis by immunophenotype. The Childrens Cancer Group. Leukemia 1994;8:856-64.

6. Petridou E, Trichopoulos D, Kalapothaki V, Pourtsidis A, Kogevinas M, Kalmanti M, Koliouskas D, Kosmidis H, Panagiotou JP, Piperopoulou F, Tzortzatou F. The risk profile of childhood leukaemia in Greece: a nationwide case-control study. Br J Cancer 1997;76: 1241-7.

7. Schuz J, Kaletsch U, Meinert R, Kaatsch P, Michaelis J. Association of childhood leukaemia with factors related to the immune system. $\mathrm{Br}$ J Cancer 1999;80:585-90.
8. Wen W, Shu XO, Linet MS, Neglia JP, Potter JD, Trigg ME, Robison LL. Allergic disorders and the risk of childhood acute lymphoblastic leukemia (United States). Cancer Causes Control 2000;11:303-7.

9. Schuz J, Morgan G, Bohler E, Kaatsch P, Michaelis J. Atopic disease and childhood acute lymphoblastic leukemia. Int J Cancer 2003;105:255-60.

10. Jourdan-Da Silva N, Perel Y, Mechinaud F, Plouvier E, Gandemer V, Lutz P, Vannier JP, Lamagnere JL, Marguerite G, Boutard P, Robert A, Armari $\mathrm{C}$, et al. Infectious diseases in the first year of life, perinatal characteristics and childhood acute leukaemia. Br J Cancer 2004;90:139-45.

11. Spector L, Groves F, DeStefano F, Liff J, Klein M, Mullooly J, Black $\mathrm{S}$, Shinefield H, Ward J, Marcy M. Vaccine safety datalink project. Medically recorded allergies and the risk of childhood acute lymphoblastic leukaemia. Eur J Cancer 2004:40:579-84.

12. Rosenbaum PF, Buck GM, Brecher ML. Allergy and infectious disease histories and the risk of childhood acute lymphoblastic leukaemia. Paediatr Perinat Epidemiol 2005;19:152-64.

13. UK Childhood Cancer Study Investigators. The United Kingdom Childhood Cancer Study: objectives, materials and methods. Br J Cancer 2000;82:1073-102.

14. Roman E, Simpson J, Ansell P, Kinsey S, Mitchell CD, Greaves M, Eden TO. Childhood acute lymphoblastic leukaemia and infections in the first year of life: a report from the United Kingdom Childhood Cancer Study. Am J Epidemiol 2007;165(5):496-504. 
15. World Health Organisation. Tenth revision of the International Statistical Classification of diseases and related health problems (ICD-10). Geneva: World Health Organisation, 1992.

16. British Medical Association, Royal Pharmaceutical Society of Great Britain. British national formulary-number 24 (September). London: British Medical Association and Pharmaceutical Press, 1992.

17. Townsend P, Phillimore P, Beattie A. Health and deprivation: inequality and the North London: Croom and Helm, 1988.

18. Williams HC. Burney PG, Hay RJ, Archer CB, Shipley MJ, Hunter JJ, Bingham EA, Finlay AY, Pembroke AC, Graham-Brown RA. The UK working party's diagnostic criteria for atopic dermatitis. I. Derivation of a minimum set of discriminators for atopic dermatitis. Br J Dermatol 1994;131:383-96.

19. Miranda C, Busacker A, Balzar S, Trudeau J, Wenzel SE. Distinguishing severe asthma phenotypes: role of age at onset and eosinophilic inflammation. J Allergy Clin Immunol 2004;113:101-8.

20. Ninan TK, Russell G. Respiratory symptoms and atopy in Aberdeen schoolchildren: evidence from two surveys 25 years apart. BMJ 1992;304:873-5.

21. Omran M, Russell G. Continuing increase in respiratory symptoms and atopy in Aberdeen schoolchildren. BMJ 1996;312:34.

22. Kaur B, Anderson HR, Austin J, Burr M, Harkins LS, Strachan DP, Warner JO. Prevalence of asthma symptoms, diagnosis, and treatment in 12-14 year old children across Great Britain (international study of asthma and allergies in childhood, ISAAC UK). BMJ 1998;316:11824.

23. Office for National Statistics (ONS). The health of children and young people. London: HMSO, 2004.

24. Burr ML, Wat D, Evans C, Dunstan FD, Doull IJ. Asthma prevalence in 1973, 1988 and 2003. Thorax 2006;61:296-9.

25. Asher MI, Montefort S, Bjorksten B, Lai CK, Strachan DP, Weiland SK, Williams H. Worldwide time trends in the prevalence of symp-

\section{Appendix}

Management Committee: KK Cheng, Central region; NE Day, East Anglia region; R Cartwright and A Craft, North East region; JM Birch and OB Eden, North West region; PA McKinney, Scotland; J Peto, South East region; V Beral and E Roman, South Midlands region; P Elwood, South Wales region; FE Alexander, South West region; CED Chilvers, Trent region; R Doll, Epidemiological Studies Unit, University of Oxford, Oxford; CM Taylor, Immunogenetics Laboratory, University of Manchester, Manchester; M Greaves, Leukaemia Research Fund Centre, Institute of Cancer Research; D Goodhead, Radiation and Genome Stability toms of asthma, allergic rhinoconjunctivitis, and eczema in childhood: ISAAC phases one and three repeat multicountry cross-sectional surveys. Lancet 2006;368:733-43.

26. Fleming S, Bodner C, Devereux G, Russell G, Campbell D, Godden D, Seaton A. An application of the United Kingdom working party diagnostic criteria for atopic dermatitis in Scottish infants. J Invest Dermatol 2001;117:1526-30.

27. Smith AG, Simpson J, Fear NT, Ansell P, Eden TO, Roman E. Child hood leukaemia and socio-economic status: fact or artefact? A report from the United Kingdom Childhood Cancer Study (UKCCS). Int J Epidemiol 2006;35(6):1504-1513.

28. Strachan DP. Hay fever, hygiene, and household size. BMJ 1989;299: 1259-60.

29. Braun-Fahrlander C, Riedler J, Herz U, Eder W, Waser M, Grize L, Maisch S, Carr D, Gerlach F, Bufe A, Lauener RP, Schierl R. Environmental exposure to endotoxin and its relation to asthma in schoolage children. N Engl J Med 2002;347:869-77.

30. Kalliomaki M, Salminen S, Poussa T, Arvilommi H, Isolauri E. Probiotics and prevention of atopic disease: 4-year follow-up of a randomised placebo-controlled trial. Lancet 2003;361:1869-71.

31. Strachan DP. Family size, infection and atopy: the first decade of the "hygiene hypothesis". Thorax 2000;55(Suppl 1):S2-S10.

32. Von Hertzen LC, Haahtela T. Asthma and atopy - the price of affluence? Allergy 2004;59:124-37.

33. Wills-Karp M, Santeliz J, Karp CL. The germless theory of allergic disease: revisiting the hygiene hypothesis. Nat Rev Immunol 2001;1:69-75.

34. Williams H, Flohr C. How epidemiology has challenged 3 prevailing concepts about atopic dermatitis. J Allergy Clin Immunol 2006;118: 209-213.

Unit, Medical Research Council, Harwell; FA Fry, National Radiological Protection Board; G Adams, UK Coordinating Committee for Cancer Research.

Regional Investigators: KK Cheng and E Gilman, Central region; NE Day, J Skinner and D Williams, East Anglia region; R Cartwright and A Craft, North East region; JM Birth and OB Eden, North West region; PA McKinney, Scotland; J Deacon and J Peto, South East region; V Beral and E Roman, South Midlands region; P Elwood, South Wales region; FE Alexander and $\mathrm{M}$ Mott, South West region; CED Chilvers and K Muir, Trent region. Data Processing Group: G Law, J Simpson and E Roman. 